\title{
PROPOSAL FOR AN INDICATIVE METHOD FOR ASSESSING AND APPORTIONING THE SOURCE OF AIR POLLUTION
}

\author{
VÍTĚZSLAV JIŘÍK*, HANA TOMÁŠKOVÁ, ONDŘEJ MACHACZKA, \\ LUCIE KISSOVÁ, BARBARA B ̌̌EŽNÁ, ANDREA DALECKÁ, \\ and VLADIMÍR JANOUT
}

Department of Epidemiology and Public Health, Faculty of Medicine, University of Ostrava, Syllabova 19, 70300 Ostrava-Zábřeh, Czech Republic

* Corresponding author: vitezslav.jirik@osu.cz

\section{ABSTRACT}

The main objective was to provide a feasible approach for approximately apportioning the sources of air pollution based on simple calculations using measured concentrations of ambient air pollutants and meteorological data. The methods are based on dividing a monitored area into sectors using a common compass rose and obtaining hourly average concentrations of pollutants and relevant data on wind direction and speed over at least three seasons of a year. As a result, the relative contributions of all sources of air pollution in an area with a monitoring station are determined, together with the absolute contributions of single or groups of sources of pollution and the levels to which the emissions need to be reduced to meet the requirements of Directive 2008/50/ESt. The proposed methods are verified using data from measuring stations complying with that required by this Directive and are suitable for improving plans aimed at reducing air pollution as defined by the same document. This approach using data for a particular area revealed a total concentration of $\mathrm{PM}_{10}$ of $22.72 \mu \mathrm{g} / \mathrm{m}^{3}$, with the maximum permissible concentration of $12.33 \mu \mathrm{g} / \mathrm{m}^{3}$ this necessitates a reduction in concentration of the contributions from this selected group sources of $10.37 \mu \mathrm{g} / \mathrm{m}^{3}$. When these simple methods are used, further and more accurate apportionments of the source could be made using more complex mathematical modelling. However, this is only necessary in areas with many sources of pollution. Although these methods cannot compete with disperse and other types of modelling they may be useful in providing a basic overview of the situation in a particular area.

Keywords: air pollution, $\mathrm{PM}_{10}$ concentration, source apportionment, Directive 2008/50/ES, pollutant monitoring, air quality improvement plans

\section{Introduction}

Air pollution is an important environmental risk factor with an unquestionable adverse effect on human health (Amodio et al. 2009; Ruiz et al. 2011). The fact that the levels of risk to health from air pollutants are not negligible is mainly due to the political and economic status of a country with a sharp contrast between social pressure toward an acceptable air quality and the financial and economic pressures for sustaining production and consumption. The policy of a democratic, law-abiding state influenced by these two opposing forces usually seeks (from a historical perspective, at least temporarily) an equilibrium as expressed in its legislation (DIRECTIVE 2008/50/ EC 2008). Such an equilibrium, however, may be easily disturbed by inadequate inspection or adherence to the adopted legal norms. Yet an apparent problem in many countries (Mijić et al. 2009; Masiol et al. 2010; Unal et al. 2011), including the Czech Republic, is non-adherence to legal limits concerning ambient air pollutants.

Health risks of ambient air pollutants acceptable for society are, among others, legislatively regulated by limit values for pollutants in the atmospheric boundary layer, particularly in residential areas or agglomerations (US EPA 2000). Legislation contains numerous requirements concerning acquisition and assessment of data on air pollution. Thus, it might be said that from a legislative point of view, the issue has been resolved. Unfortunately, the opposite is true since the regulations do not answer the fundamental questions of what is the contribution of individual sources of pollution to the overall pollution in a particular area, for which sources corrective measures are needed to improve air quality and the extent to which the regulations are not adhered to in that area. Such solutions should be primarily fair, reliable and simple so that they could be implemented using data that are collected as required by the above legislation and thus are immediately available.

Currently, the contribution to air pollution of individual sources is usually determined from data on sources of emission (Juda-Rezler et al. 2006; Srivastava et al. 2008; Viana et al. 2008; Thimmaiah et al. 2009; Mooibroek et al. 2011) using dispersion (diffusion) models (Perez-Roa et al. 2006). Given the fact that emissions are spread in the air by diffusion and flow of air and the relations describing these phenomena are relatively complicated (Cimorelli et al. 2004), dispersion models used to calculate air pollutant concentrations utilize many simplifications, leading to results different from the measured data. Although mathematical models are indispensable for predicting air pollution and additional calculations related to the measured data, this approach has other practical drawbacks. One example is the frequent unreliability of 
officially reported data on emissions, another the irrelevant results of dispersion studies due to unavailable data on some sources of pollution in the monitored area.

This article proposes methods that preferably use accurate data that are an increasingly reliable source of information on air pollution as compared with dispersion models and are thus, in accordance with valid legislation, a critical starting point for assessing higher emission loads, that is, those close to or beyond the limit values. The objective of the methods is to use as simple processing of the measured data as possible (Xiao et al. 2012) and additional dispersion models to estimate the contribution of individual sources of pollution in a particular area so that these data may be used as a starting point for adopting regional programs for reducing air polluting emissions, which determine mandatory corrective measures aimed at improving air quality and reducing risks to health.

\section{Materials and Methods}

\section{Measurements}

The input data set comprises hourly average concentrations $\left(\mathrm{C}_{\mathrm{h}}\right)$ of ambient air pollutants. The approach is used for pollutants transported to a monitoring station in a particular area by diffusion and flow of air from all surrounding sources. Data on pollutant concentrations obtained from fixed monitoring stations are in accordance with Directive 2008/50/EC of the European Parliament
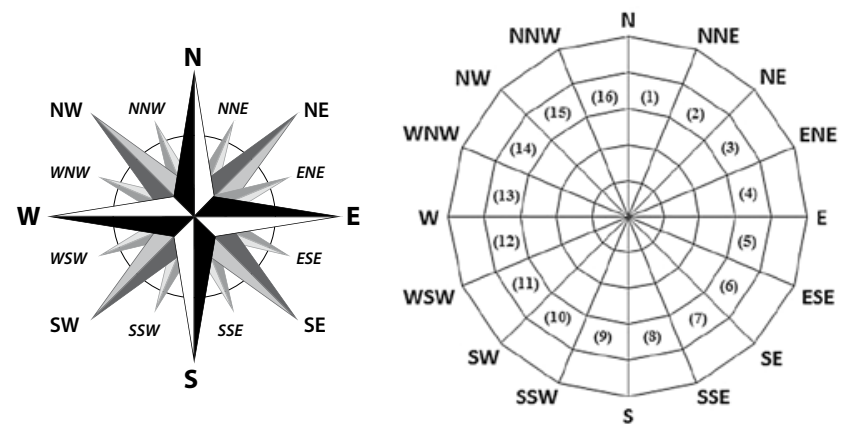

Fig. 1 Wind rose divided into 16 sectors.

and the Council (hereinafter the Directive) (Directive 2008/50/EC Chapter 5 2008) are, for the purposes of public health protection, considered valid and representative for the entire location.

Hourly data on pollutant concentrations $\left(C_{h}\right)$ and wind direction and speed must be acquired over a longer time period (Hrust et al. 2009) to eliminate seasonal and yearly fluctuations and ensure that the average concentrations over the entire period are really representative for the area. The longer time period refers to the time for which the Average Exposure Indicator is calculated in accordance with the Directive, for example, 3 years.

A monitored area may be divided into sectors ( $k$; directions as defined angles with vertices at a sampling point) according to the cardinal, intercardinal and secondary intercardinal points (Fig. 1).

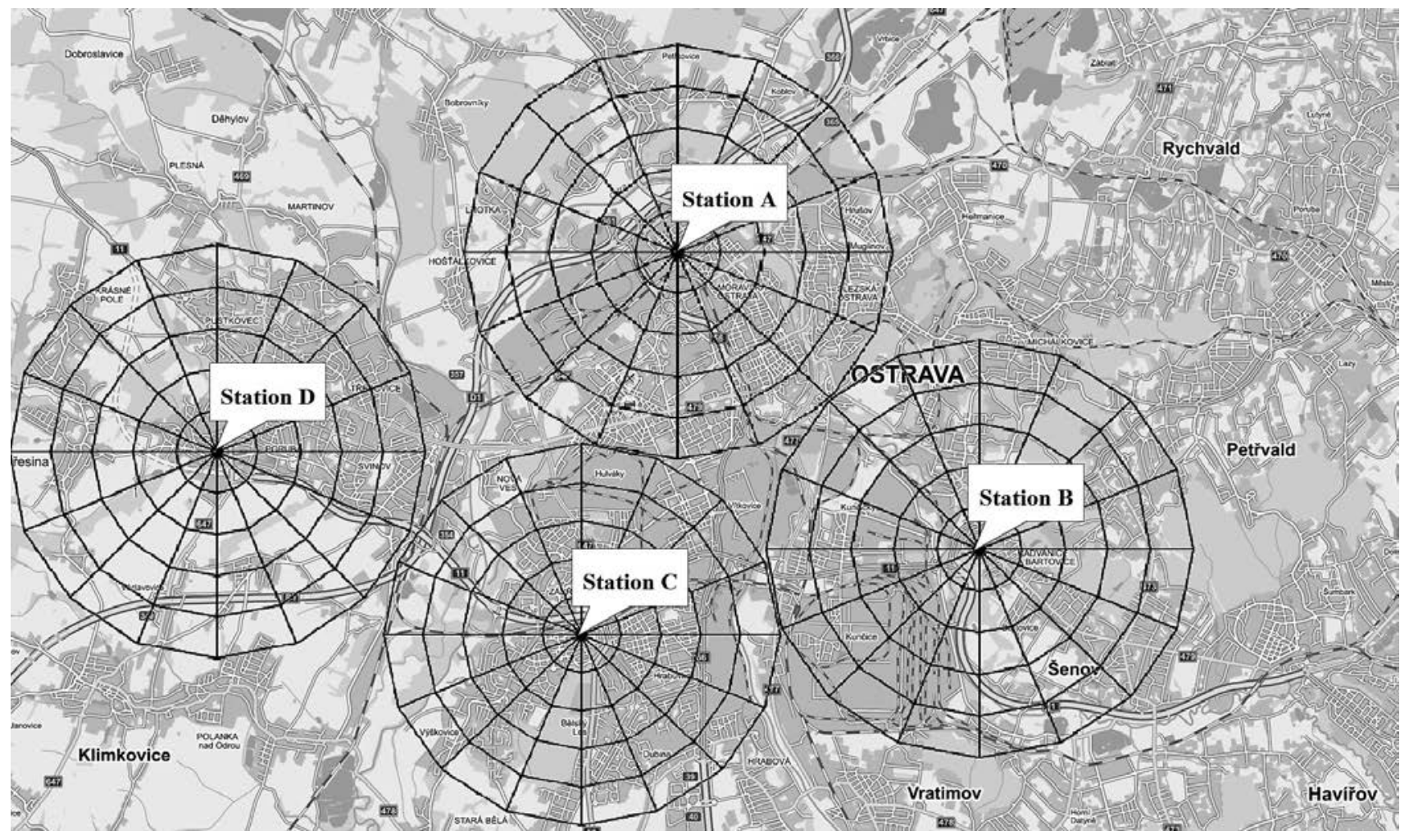

Fig. 2 An example of four monitoring stations and related wind roses. 
Such division into sectors may be used for all monitored areas, with sectors having their vertices at the sampling points (Fig. 2).

The data on hourly average concentrations $\left(\mathrm{C}_{h}\right)$ of an air pollutant, hourly average wind direction and speed values may be used to calculate average concentrations $\left(\mathrm{C}_{\mathrm{k}}\right)$ of the pollutant for individual sectors over the entire time period as follows:

$$
C_{k}=\frac{\sum_{h=1}^{N_{k}} C_{k h}}{N_{k}}\left[\mu \mathrm{g} \mathrm{m}^{-3}\right]
$$

Where:

- $k$ is the sector (each sector is an angle of $22.5^{\circ}$; see Fig. 1);

- $h$ is the hourly value, or average value per hour;

- $C_{k h}\left[\mu \mathrm{g} \mathrm{m}^{-3}\right]$ is the hourly average concentration of the pollutant in the air at an hourly average wind direction $u_{k}>0.5 \mathrm{~m} \mathrm{~s}^{-1}$ from sector $k$;

- $N_{k}$ is the number (frequency) of hourly average wind directions (and measured concentrations $C_{k h}$ ) over the entire time period from sector $\mathrm{k}$; and

- $C_{k}\left[\mu \mathrm{g} \mathrm{m}^{-3}\right]$ is the average concentration of the pollutant in the air over the entire time period with an hourly average mean direction $u_{k}>0.5 \mathrm{~m} \mathrm{~s}^{-1}$ from sector k.

Authors' note: The average or median value of a set of data on concentrations of a pollutant should be calculated with regard to the statistical distribution of the data. When determining average concentrations in compliance with legislation valid in EU countries, this approach is not used and the law requires that median values are calculated as arithmetic means. Such an approach, however, is not statistically correct.

Thus, the average concentrations $C_{k}$ represent partial concentrations of the pollutant at a sampling point in a monitored area carried by the air flow from a particular circular sector downwind if the wind speed is $\overline{\mathrm{u}}_{h}>0.5 \mathrm{~m} \mathrm{~s}^{-1}$. Under calm wind conditions, i.e. $\overline{\mathrm{u}}_{h} \leq 0.5 \mathrm{~m} \mathrm{~s}^{-1}$, the average concentration at the sampling point $\left(\mathrm{C}_{\mathrm{s}}\right)$ is calculated as follows:

$$
C_{s}=\frac{\sum_{h=1}^{N_{S}} C_{s h}}{N_{S}}\left[\mu \mathrm{g} \mathrm{m}^{-3}\right]
$$

Where $C_{s h}\left[\mu \mathrm{g} \mathrm{m}^{-3}\right]$ is the hourly average concentration of the pollutant under calm wind conditions, i.e. $u_{k} \leq 0.5 \mathrm{~m} \mathrm{~s}^{-1}$ (US EPA 2000), and $N_{s}$ is the number (frequency) of concentrations $C_{s h}$ measured over the entire period. The lower and upper limits of the confidence interval (at a significance level of 95\%) for the average concentrations $C_{k}$ and $C_{s}$ are referred to as $C_{k 95 L}, C_{k 95 H}$, $C_{s 95 L}$ and $C_{s 95 H}$, respectively. These may be used to determine the significance of differences in concentrations between individual sectors or concentrations under calm wind conditions.

Relative frequencies $R_{k}$ and $R_{s}$ may be expressed as quotients:

$$
\begin{aligned}
& R_{k}=\frac{N_{k}}{\left(\sum_{k=1}^{16} N_{k}\right)+N_{S}} \\
& R_{S}=\frac{N_{S}}{\left(\sum_{k=1}^{16} N_{k}\right)+N_{S}}
\end{aligned}
$$

with

$$
\left(\sum_{k=1}^{16} R_{k}\right)+R_{s}=1
$$

Relative contributions $P_{k}$ and $P_{s}$ of the pollutant may be estimated from average concentrations $C_{k}$ and $C_{s}$ of the pollutant and relevant frequencies $N_{k}$ and $N_{s}$, respectively:

$$
\begin{gathered}
P_{k}=\frac{N_{k} C_{k}}{\left(\sum_{k=1}^{16} N_{k} C_{k}\right)+N_{S} C_{S}} \\
P_{S}=\frac{N_{S} C_{S}}{\left(\sum_{k=1}^{16} N_{k} C_{k}\right)+N_{S} C_{S}}
\end{gathered}
$$

with

$$
\left(\sum_{k=1}^{16} P_{k}\right)+P_{S}=1
$$

Concentrations $C_{k}$ and $C_{s}$ and frequencies $N_{k}$ and $N_{s}$ may be used to calculate the average concentration $C_{m}$ in the monitored area:

$$
C_{m}=\frac{\left(\sum_{k=1}^{16} N_{k} C_{k}\right)+N_{S} C_{S}}{\left(\sum_{k=1}^{16} N_{k}\right)+N_{S}}\left[\mu \mathrm{g} \mathrm{m}^{-3}\right]
$$

Similarly, concentration contributions $D_{k}$ and $D_{s}$ may be calculated, using either relative contributions $P_{k}$ and $P_{s}$, respectively, and the average concentration $C_{m}$ or relative frequencies $R_{k}$ and $R_{s}$, respectively, and the average concentration $C_{k}$ :

$$
\begin{aligned}
& D_{k}=P_{k} C_{m}=R_{k} C_{k}\left[\mu \mathrm{g} \mathrm{m}^{-3}\right] \\
& D_{s}=P_{s} C_{m}=R_{s} C_{s}\left[\mu \mathrm{g} \mathrm{m}^{-3}\right]
\end{aligned}
$$

with

$$
\left(\sum_{k=1}^{16} D_{k}\right)+D_{s}=C_{m}
$$

This approach corresponds with that used in dispersion models where long-term (yearly) concentrations of a pollutant are the sum of contributions corresponding to concentrations for individual standardized meteorological situations multiplied by the average frequency of these situations (Bubník et al. 1998). As is the case with $D_{k}$ and $D_{s}$, relative frequencies $R_{k}$ and $R_{s}$ and a selected limit value LV may be used to determine maximum permissible concentration contributions $D_{k, \max }$ and $D_{s, \max }$ respectively:

$$
\begin{aligned}
& D_{k, \text { max }}=R_{k} L V\left[\mu \mathrm{g} \mathrm{m}^{-3}\right] \\
& D_{s, \text { max }}=R_{s} L V\left[\mu \mathrm{g} \mathrm{m}^{-3}\right]
\end{aligned}
$$

If concentration contributions $D_{k}$ or $D_{s}$ are greater than maximum permissible concentration contributions 
$D_{k, \max }$ and $D_{s, \max }$, respectively, necessary reductions in concentration contributions in sectors $\mathrm{k}$ may be simply determined as follows:

$$
\begin{aligned}
\Delta D_{k} & =D_{k}-D_{k, \text { max }}\left[\mu \mathrm{g} \mathrm{m}^{-3}\right] \\
\Delta D_{s} & =D_{s}-D_{s, \max }\left[\mu \mathrm{g} \mathrm{m}^{-3}\right]
\end{aligned}
$$

No reductions in emission contributions are needed if $\Delta D_{k} \leq 0$ and $\Delta D_{s} \leq 0$. Concentration contributions $D_{k}$ may be considered as minimum since they do not involve contributions from sources under calm wind conditions although they affect the area. This is expressed by concentration contribution $D_{s}$, a sum of all concentration contributions from all surrounding sources in the area under calm wind conditions that is unable to provide adequate information about contributions of sources in individual sectors $\mathrm{k}$. This contribution may be apportioned among individual sectors or sources using approaches for calm wind periods in dispersion models (Bubník et al. 1998).

The total concentration contribution $D_{s}$ over a calm wind period may be roughly apportioned among sectors $\mathrm{k}$ or individual sources $\mathrm{j}$ according to the following formula, assuming that the emission flow of the pollutant resembles a cylinder with radius $X$ and height $L$ :

$$
D_{s k j}(\text { calc }) \cong \frac{Q_{k j} \cdot C F \cdot T_{S}}{2 \pi \cdot X_{k j}^{2} \cdot L}\left[\mu \mathrm{g} \mathrm{m}^{-3}\right]
$$

with

$$
\sum_{k=1}^{16} \sum_{j=1}^{N_{k j}} D_{s k j}=D_{s}
$$

In addition to emission flow of a source $Q_{k j}$ [t/year] and its distance from a sampling point $X_{k j}[\mathrm{~m}]$, such a concentration contribution is also dependent on duration $T_{s}$ of the calm wind period and the average height of the atmospheric mixed layer $L[\mathrm{~m}]$ (US EPA 1999). The conversion factor $C F$ is $114,155.25$ [year $\times \mu \mathrm{g} / \mathrm{h} \times \mathrm{t}$ ]. Although this is only a rough estimate as it does not consider, for instance, the height of sources (a more accurate estimate requires the use of a dispersion model for calm wind conditions), it is sufficient for the purpose as seen from experimental data. The reliability of the estimate may be considerably increased if nearly all sources are considered and the fulfillment of the condition in formula (15) may be verified.

Thus, concentration contributions of sources $j$ in sectors $\mathrm{k}$ are calculated as follows:

$$
D_{k, t o t}=D_{k}+\sum_{j=1}^{N_{k j}} D_{s k j}\left[\mu \mathrm{g} \mathrm{m}^{-3}\right]
$$

where $N_{k j}$ is the number of sources $j$ in sector $k$.

Maximum permissible concentration contributions of individual sources under calm wind conditions may be roughly estimated in sixteen sectors $k$ by evenly apportioning maximum permissible concentration contribution $D_{s}$ among all the considered sources $j$ :

$$
D_{s k j, \max }=D_{s} /\left(N_{k j} \cdot 16\right)
$$

with

$$
\sum_{k=1}^{16} \sum_{j=1}^{N_{k j}} D_{s k j, \max }=D_{s, \max }
$$

Therefore, total maximum permissible contributions of sources in sectors $k$ are calculated as follows:

$$
D_{k, \max , \text { tot }}=D_{k, \max }+\sum_{j=1}^{N_{k j}} D_{s k j, \max }\left[\mu \mathrm{g} \mathrm{m}^{-3}\right]
$$

Total necessary reductions in concentration contributions of all sources in sectors $k$ are calculated as:

$$
\Delta D_{k, t o t}=D_{k, t o t}-D_{k, \text { max }, \text { tot }}\left[\mu \mathrm{g} \mathrm{m}^{-3}\right]
$$

If a selected sector $k$ contains $N_{k j}$ sources, an adequate dispersion model, i.e. calculation, may be used to determine the relevant concentration contributions $D_{k j}($ calc $)$ valid at the sampling point. In this case, data on concentrations are obtained not from measurements but from a dispersion model and may not therefore be valid (see the reasons stated in the Introduction). Validity of dispersion model results may be simply verified using the following formula for summing up concentration contributions $D_{k j}($ calc $)$ :

$$
\sum_{j=1}^{N_{k j}} D_{k j}(\text { calc })=D_{k, t o t}\left[\mu \mathrm{g} \mathrm{m}^{-3}\right]
$$

If the relation is not fulfilled, data on concentrations from the dispersion model do not correspond with the measured data and model calculation results have to be corrected. Necessary reductions in concentration contribution $\Delta D_{k j}$ of a source in the monitored area may be determined analogically to those in case of $\Delta D_{k}$, as seen from formula (15):

$$
\Delta D_{k j}=D_{k j}(\text { calc })-D_{k, \text { max }, \text { tot }}\left[\mu \mathrm{g} \mathrm{m}^{-3}\right]
$$

Additionally, a suitable dispersion model and the necessary reductions in concentration contributions in the particular area may be used to determine necessary reductions of emissions for each source, potentially leading to adherence to the adopted limit values.

\section{Equipment and Software}

To verify the methods, data from monitoring stations were processed with the statistical software Stata (Stata Corp., Release 9, College Station, Texas, USA) and the spreadsheet program Excel (Microsoft Corp., Worldwide, USA).

\section{Results}

The above methods were verified using experimental data from measuring stations in some boroughs of the city of Ostrava included in the national network consis- 


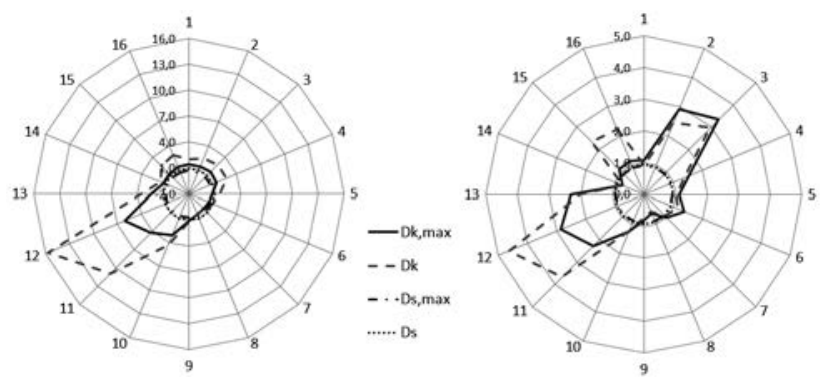

Fig. 3 Average concentrations of $\mathrm{PM}_{10}$ in the air obtained from measuring station $B$ in winter and summer.

tent with the Directive. The measuring station in one of the city boroughs (Radvanice and Bartovice) is referred to as B in Fig. 2. In this as well as other areas of the city, measuring stations recorded readings above limit values for pollutants, especially particulate matter. All hourly average concentrations and data on wind direction and speed were obtained over several years (all seasons over a period of six years).

Data used to verify the above method are graphically summarized in Fig. 3 for $\mathrm{PM}_{10}$ and in Fig. 4 for $\mathrm{NO}_{2}$. The detailed results are listed only for $\mathrm{PM}_{10}$ in numerical form because of the possible scope of the article, as a demonstration of the above method.
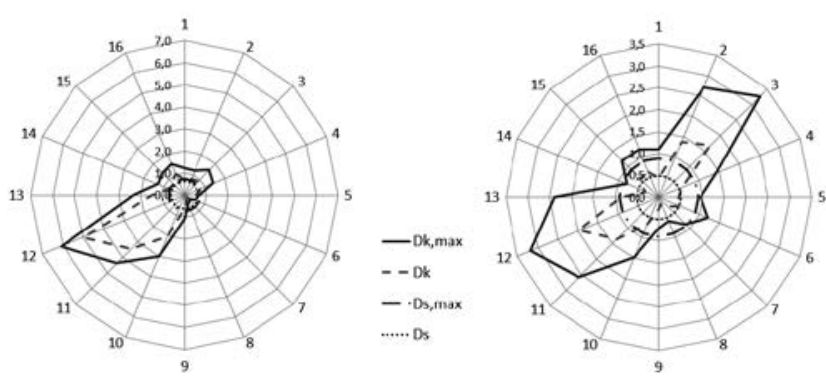

Fig. 4 Average concentrations of $\mathrm{NO}_{2}$ in the air obtained from measuring station $B$ in winter and summer.

Table 1 clearly shows that relative contributions of pollutants from sectors $k=10,11$ and 12 are $\Sigma P_{k}=0.34$ and relative contributions from all sectors under calm wind conditions are $P_{s}=0.30$. This corresponds with concentration contributions $\Sigma D_{k}=20.28\left[\mu \mathrm{g} / \mathrm{m}^{3}\right]$ and $D_{s}$ $=17.85\left[\mu \mathrm{g} / \mathrm{m}^{3}\right]$. If maximum permissible concentration contributions are $D_{k, \max }=9.91\left[\mu \mathrm{g} / \mathrm{m}^{3}\right]$ for these three sources and $D_{s, \max }=12.88\left[\mu \mathrm{g} / \mathrm{m}^{3}\right]$ for all sectors under calm wind conditions, the necessary reductions in concentration contributions are $\Delta D_{10,11,12}=10.37\left[\mu \mathrm{g} / \mathrm{m}^{3}\right]$ and $\Delta D_{s}=4.97\left[\mu \mathrm{g} / \mathrm{m}^{3}\right]$, respectively.

There are numerous important sources of pollution in Ostrava. To illustrate the application of the above meth-

Table 1 Parameters of the proposed method for $\mathrm{PM}_{10}$ obtained from the B measuring station.

\begin{tabular}{|c|c|c|c|c|c|c|c|c|c|}
\hline \multicolumn{10}{|c|}{$\mathrm{PM}_{10}$ Limit value $\left[\mu \mathrm{g} \mathrm{m}^{-3}\right]=40$} \\
\hline Units & - & - & [ $\left.\mathrm{\mu g} \mathrm{m}^{-3}\right]$ & {$\left[\mu \mathrm{g} \mathrm{m}^{-3}\right]$} & {$\left[\mu \mathrm{g} \mathrm{m}^{-3}\right]$} & - & {$\left[\mu \mathrm{g} \mathrm{m}^{-3}\right]$} & {$\left[\mu \mathrm{g} \mathrm{m}^{-3}\right]$} & {$\left[\mu \mathrm{g} \mathrm{m}^{-3}\right]$} \\
\hline Sector $k$ & $\mathbf{N}_{\mathbf{k}}$ & $\mathbf{R}_{\mathbf{k}}$ & $C_{k 95 L}$ & $\mathrm{C}_{\mathrm{k95H}}$ & $C_{k}$ & $\mathbf{P}_{\mathbf{k}}$ & $D_{k}$ & $D_{k, \max }$ & $\Delta \mathrm{D}_{\mathrm{k}}$ \\
\hline 1 & 1301 & 0.0311 & 45.31 & 48.85 & 47.08 & 0.0243 & 1.47 & 1.25 & 0.22 \\
\hline 2 & 2255 & 0.0540 & 43.96 & 46.90 & 45.43 & 0.0407 & 2.45 & 2.16 & 0.29 \\
\hline 3 & 2588 & 0.0619 & 44.74 & 47.56 & 46.15 & 0.0474 & 2.86 & 2.48 & 0.38 \\
\hline 4 & 1566 & 0.0375 & 51.76 & 57.04 & 54.40 & 0.0338 & 2.04 & 1.50 & 0.54 \\
\hline 5 & 965 & 0.0231 & 53.00 & 58.68 & 55.84 & 0.0214 & 1.29 & 0.92 & 0.37 \\
\hline 6 & 1013 & 0.0242 & 39.79 & 43.53 & 41.66 & 0.0168 & 1.01 & 0.97 & 0.04 \\
\hline 7 & 724 & 0.0173 & 37.60 & 41.58 & 39.59 & 0.0114 & 0.69 & 0.69 & -0.01 \\
\hline 8 & 582 & 0.0139 & 36.34 & 40.72 & 38.53 & 0.0089 & 0.54 & 0.56 & -0.02 \\
\hline 9 & 981 & 0.0235 & 37.23 & 41.05 & 39.14 & 0.0152 & 0.92 & 0.94 & -0.02 \\
\hline 10 & 2265 & 0.0542 & 50.15 & 53.09 & 51.62 & 0.0464 & 2.80 & 2.17 & 0.63 \\
\hline 11 & 3437 & 0.0822 & 87.15 & 90.51 & 88.83 & 0.1212 & 7.31 & 3.29 & 4.02 \\
\hline 12 & 4655 & 0.1114 & 89.77 & 92.91 & 91.34 & 0.1688 & 10.17 & 4.46 & 5.72 \\
\hline 13 & 2445 & 0.0585 & 46.14 & 49.00 & 47.57 & 0.0462 & 2.78 & 2.34 & 0.44 \\
\hline 14 & 1017 & 0.0243 & 45.15 & 49.82 & 47.49 & 0.0192 & 1.16 & 0.97 & 0.18 \\
\hline 15 & 1247 & 0.0298 & 77.02 & 85.08 & 81.05 & 0.0401 & 2.42 & 1.19 & 1.22 \\
\hline 16 & 1290 & 0.0309 & 78.90 & 85.52 & 82.21 & 0.0421 & 2.54 & 1.23 & 1.30 \\
\hline \multirow{2}{*}{ Forwind } & $\Sigma N_{k}$ & $\Sigma \boldsymbol{R}_{\boldsymbol{k}}$ & $C_{w 95 L}$ & $C_{w 95 H}$ & $C_{w}$ & $\boldsymbol{\Sigma} \boldsymbol{P}_{\boldsymbol{k}}$ & $\Sigma D_{k}$ & $\sum D_{k, \max }$ & $\Sigma \Delta D_{k}$ \\
\hline & 28331 & 0.6779 & 60.67 & 64.50 & 62.58 & 0.7039 & 42.43 & 27.12 & 15.31 \\
\hline \multirow{2}{*}{ Windless } & $N_{s}$ & $R_{s}$ & $C_{s 95 L}$ & $C_{s 95 H}$ & $C_{s}$ & $P_{s}$ & $D_{s}$ & $D_{s, \max }$ & $\Delta D_{s}$ \\
\hline & 13461 & 0.3221 & 54.67 & 56.17 & 55.42 & 0.2961 & 17.85 & 12.88 & 4.97 \\
\hline \multirow{2}{*}{ Total } & $\Sigma N_{k}+N_{s}$ & $\Sigma R_{k}+R_{s}$ & $C_{m 95 L}$ & $C_{m 95 H}$ & $C_{m}$ & $\Sigma P_{k}+P_{s}$ & $\Sigma D_{k}+D_{s}$ & $\sum D_{k, \text { max }}+D_{s, \text { max }}$ & $\Sigma \Delta D_{k}+\Delta D_{s}$ \\
\hline & 41792 & 1.0000 & 58.74 & 61.81 & 60.28 & 1.0000 & 60.28 & 40.00 & 20.28 \\
\hline
\end{tabular}




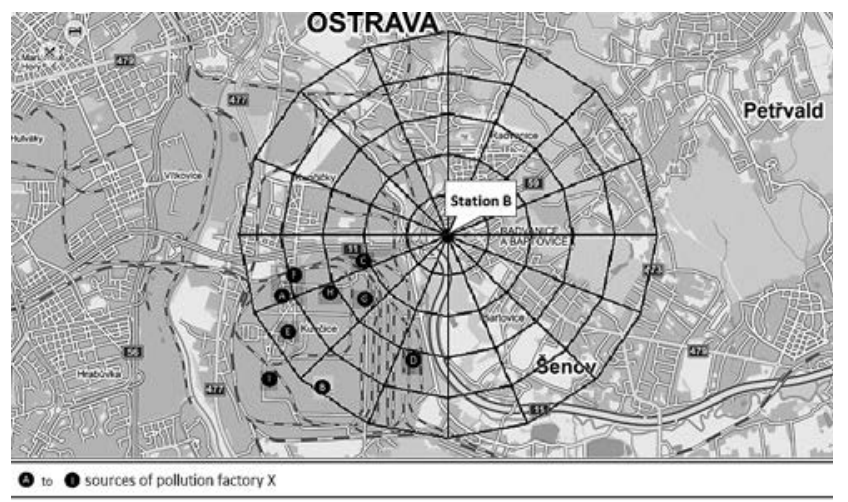

Fig. 5 Distribution of pollution sources around measuring station B.

od, several sources of pollution in Plant $X$ were selected which are found in sectors $k=10,11$ and 12 (see Fig. 5).

Concentration contribution $D_{s}$ and the relevant necessary reduction $\Delta D_{s}$ for all sources under calm wind conditions may be divided into concentration contributions for individual sources $D_{s k j}$ and necessary reductions in concentration contributions for individual sources under calm wind conditions $\Delta D_{s k j}$ using formulae (17) to (22). For sources shown in Fig. 5, characterized by variables $Q_{k j}=1246.48$ [t/year], $X_{k j}=2599$ [m] for distances of sources from the sampling point from 1570 up to 3670 meters, $T_{s}=50[\mathrm{~h}], L=200[\mathrm{~m}]$ (CHMI, 2008), are calculated: $D_{s k j}=1.27\left[\mu \mathrm{g} / \mathrm{m}^{3}\right], D_{\text {skj, } \text { max }}=2,42\left[\mu \mathrm{g} / \mathrm{m}^{3}\right]$ and $\Delta D_{s k j}=-1.14\left[\mu \mathrm{g} / \mathrm{m}^{3}\right]$.

Thus, the total concentration contribution for all sources in sectors $k=10,11$ and 12 is $D_{k, t o t}=20.28+$ $1.27=21.55\left[\mu \mathrm{g} / \mathrm{m}^{3}\right]$, the maximum permissible concentration contribution is $D_{\text {kmax, tot }}=9.91+2.42=12.33$ $\left[\mu \mathrm{g} / \mathrm{m}^{3}\right]$ and $\Delta \mathrm{D}_{k, t o t}=10.37+(-1.14)=21.55-12.33=$ $9.22\left[\mu \mathrm{g} / \mathrm{m}^{3}\right]$.

This example is described in order to establish the validity of the above method.

\section{Discussion}

The above methods propose several parameters simply describe the estimation of concentration contributions of individual sources or groups of sources to pollution of a particular area. Such pollution, if approximately equal to or greater than the limit values, must be, in accordance with the Directive (DIRECTIVE 2008/50; EC 2008) assessed using measured data and not dispersion (Bubník 1998; Cimorelli et al. 2004) or receptor (Hopke et al. 2010; Zeng et al. 2010) modelling. This rule is respected by the proposed methods and the parameters are calculated exclusively from measured data and modelling may only be used to obtain more accurate results.

The basic parameter of the methods is relative contribution $P_{k}$ of a selected pollutant brought to the monitored area from a particular direction (i.e. sector k; see formulae (1) to (6) in section Measurements, if the wind speed is $>0.5 \mathrm{~m} / \mathrm{s}$ (i.e. not under calm wind conditions; see below) (Donnelly et al. 2011; Henry et al. 2012). To determine this parameter, more detailed measured data should be used, such as hourly average concentrations and corresponding hourly average wind direction and speed values over a longer time period. Given the relatively large amount of such data (theoretically, 365 days $\times$ 24 hours $=8,760$ hourly values), high statistical power of the results may be assumed; fluctuations in annual data (from all seasons) should be compensated for by using data obtained over three or more years (similar to the Average Exposure Indicator as defined by the Directive). In the present study, hourly values obtained over six years were used, with the number of values (sum of $N_{k}$ ) from a single measuring station exceeding 40,000 (see Table 1). Concentration contribution $D_{k}$ of a pollutant is simply calculated from relative contribution $P_{k}$ and average concentration in the area $C_{m}$, see formula (10).

The above parameters are not valid under calm wind conditions, that is, if wind speed exceeds $0.5 \mathrm{~m} / \mathrm{s}$. Although this value was also experimentally determined in this study, the results are beyond the scope of this article. Since the value found in the present study is consistent with that published by the US EPA (AERMOD, 2004), calm wind conditions were defined as wind speed $\leq 0.5 \mathrm{~m} / \mathrm{s}$. Given the fact that under calm wind conditions, all neighbouring sources contribute to pollution at the sampling site, parameters for all sources in the area together were first calculated, that is, relative contribution $\mathrm{P}_{\mathrm{s}}$ using formula (7), concentration contribution $D_{s}$ using formula (11) and maximum permissible concentration contribution $D_{\text {smax }}$ using formula (14), and then apportioned among individual sources. For such apportionment, the following must be known: emission flow of sources of the pollutant $Q_{k j}$, distance of sources from the sampling point $X_{k j}$, height of the atmospheric boundary layer $\mathrm{L}$ and average duration of calm wind periods $T_{s}$. Although this is only a rough approximation that may not provide accurate results for areas and sources that differ considerably in height, our experiences have shown that it is likely to be applicable in most cases. However, it must be remembered that the calculation is only used for calm wind conditions, which are rather sporadic in some areas. In the area monitored in the present study, calm wind conditions accounted for approximately $30 \%$ of the 6 -year period (see $R_{s}$ in Table 1), that is, they were relatively very common (the monitored area is known for frequent and long periods of smog and calm wind). Yet, based on our experiences with monitoring and dispersion modelling, the results obtained with the aforementioned methods are not far from the truth. The average height of the atmospheric mixed layer L may be calculated or measured (US EPA 1999).

The proposed methods have been practically verified by calculations using accurate data. The article shows sample calculations related to several sources of pollution within a single large industrial Plant $X$ on the outskirts of a city (a population of approximately 300,000 ) and a 
measuring station located in a residential area considerably affected by them. The long-term average concentration of $\mathrm{PM}_{10}$ was $60.3 \mu \mathrm{g} / \mathrm{m}^{3}$, with the limit value being set at $40 \mu \mathrm{g} / \mathrm{m}^{3}$. Thus, to meet the limit value, the amount of particulate matter emissions from the sources in the plant would have to be reduced by $\Delta D_{k}=10.37\left[\mu \mathrm{g} / \mathrm{m}^{3}\right]$ under windy conditions and by $\Delta D_{s k j}=-1.14\left[\mu \mathrm{g} / \mathrm{m}^{3}\right]$ under calm conditions at the site of the measuring station, that is, by a total of $\Delta \mathrm{D}_{\mathrm{k}, \mathrm{tot}}=9.22\left[\mu \mathrm{g} / \mathrm{m}^{3}\right]$. To achieve the total necessary reduction in concentration contributions $\Sigma \Delta D_{k}+\Delta D_{s}=20.28\left[\mu \mathrm{g} / \mathrm{m}^{3}\right]$, the other sources account for the remaining reduction by $11.06\left[\mu \mathrm{g} / \mathrm{m}^{3}\right]$.

Data on the necessary reduction of concentration contributions $\Delta D_{k \text {,tot }}$ may be used by the source operator to model the amount of pollutants emitted by the source to meet the limit values for pollutants in ambient air, that is, not only the emission limits. Moreover, these data should include national and regional action plans that, in accordance with the Directive, should ensure that the population is exposed to acceptable air pollutant levels over a defined period of time. If the plans for reducing concentrations of air pollutants only contain technical measures to reduce emissions and the unsatisfactory condition is not corrected over time, the source operator remains unpunished and the population continues to be exposed to increased health risks.

\section{Conclusion}

The presented approximate source apportionment is a simple mathematical application using measured data available from any measuring station compliant with Directive 2008/50/EC, that is, where limit values for ambient air pollutants are exceeded. Data on concentrations of ambient air pollutants, corresponding meteorological data and some available data on sources of air pollution and their groups are used to calculate concentration contributions of selected pollutants relevant to individual sources. Subsequently, necessary reduction of these concentrations is determined so that the total contribution of all sources does not exceed the limit values defined by the Directive. The methodology was tested using data relevant to a particular source of pollutants.

Although the above methods are only a first approximation for obtaining information on source apportionment in a monitored area they may be a sufficient and fair starting point for developing air quality plans in accordance with the Directive. Unfortunately, the document does not contain even minimal guidance on how to make individual source operators reduce their emissions. If air quality plans developed in accordance with the Directive comprised requirements for reduction of concentration contributions, the presented approximate methods could be used to determine maximum permissible concentration contributions of every source more accurately so that the limit values are adhered to. The presented cal- culations for a selected group of sources within a single large plant demonstrate the practical use of the methods. The total contribution of the plant adjacent to a residential area where a monitoring station is located was $20.28 \mu \mathrm{g} / \mathrm{m}^{3}$, being composed of a contribution under non-zero air flow conditions and a contribution under calm conditions. To ensure that the limit values as defined by the Directive are not exceed in the zone, when all sources of pollution are considered, the contribution would have to be reduced by $10.37 \mu \mathrm{g} / \mathrm{m}^{3}$. This requirement should be incorporated in the ambient air quality improvement plan so that reverse modelling could be used to define relevant reductions of emissions for each source and the feasibility or non-feasibility of corrective measures could be determined, potentially leading to additional decisions. After the time limit for applying corrective measures expires, fulfillment of the requirement implemented in the air quality plan may be checked using the same methods.

\section{REFERENCES}

Amodio M, Caselli M, de Gennaro G, Tutino M (2009) Particulate PAHs in two urban areas of Southern Italy: Impact of the sources meteorological and background conditions on air quality. Environ Res 1009: 812-820.

Bubník J, Keder J, Macoun J, Maňák J (1998) System modeling stationary sources for calculating air pollution from point, area and line sources. Version 97. Czech Hydrometeorological Institute, Praha.

Bubník J, Keder J, Macoun J, Maňák J (1998) System modeling stationary sources (addition for version 97). Czech Hydrometeorological Institute, Praha.

Cimorelli AJ, Perry SG, Venkatram A, Weil JC, Paine RJ, Wilson RB, Lee RF, Peters WD, Brode RW, Paumier JO, Thurman J (2004) AERMOD: Description of model formulation No. EPA454/R-03-004.US EPA.

Czech Hydrometeorological Institute [online]. Praha: Czech Hydrometeorological Institute, 2008, cit. 11 July 2016, available on: http://portal.chmi.cz.

Devraj T, Hovorka J, Hopke PK (2009) Source apportionment of winter submicron Prague aerosols from combined particle number size distribution and gaseous composition data. Aerosol Air Qual Res 9: 209-236.

DIRECTIVE 2008/50/EC of European Parliament and of the Council of 21 May 2008 on ambient air quality and cleaner air for Europe.

DIRECTIVE 2008/50/EC of European Parliament and of the Council of 21 May 2008 on ambient air quality and cleaner air for Europe, Chapter 5.

Donnelly A, Misstear B, Broderic B (2011) Application of nonparametric regression methods to study the relationship between $\mathrm{NO}_{2}$ concentration and local wind direction and speed at backgroundsites. Sci Total Environ 409: 1134-1144.

Henry RC, Chang Y, Spiegelman CH (2002) Locatingnearby sources of air pollution by nonparametric regression of atmospheric concentrations on wind direction. Atmos Environ 36: 2237-2244

Hopke PK (2010) The application of receptor modelling on air quality data. Pollut Atmos No. Sep: 91-109. 
Hrust L, Klaic ZB, Križan J, Antonic O, Hercog P (2009) Neural network forecasting of air pollutants hourly concentrations using optimised temporal averages of meteorological variables and pollutant concentrations. Atmos Environ: 43: 5588-5596.

Juda-Rezler K, Reizer M, Oudinet JP (2011) Determination and analysis of $\mathrm{PM}_{10}$ sources apportionment during episodes of air pollution in Central Eastern European urban areas. The case of wintertime 2006. Atmos Environ 45: 6557-6566.

Masiol M, Rampazzo G, Ceccato D, Squizzato S, Pavoni B (2010) Characterisation of $\mathrm{PM}_{10}$ sources in a coastal area near Venice (Italy): An application of factor-cluster analysis. Chemosphere 80: 771-778.

Mijić Z, Tasić M, Rajšić S, Novaković V (2009) The statistical characters of $\mathrm{PM}_{10}$ in Belgrade area. Atmos Res 92: 420-426.

Mooibroek D, Schaap M, Weijers EP, Hoogerbrugge R (2011) Source apportionment and spatial variability of $\mathrm{PM}_{2.5}$ using measurements at five sites in the Netherlands. Atmos Environ 45: 4180-4191.

Perez-Roa R, Castro J, Jorquera H, Perez-Roa JR, Vesovic V (2006) Air pollution modelling in an urban area: Correlating turbulent diffusion coeficients by means of an artificial neural network approach. Atmos Environ 40: 109-125.

Ruiz S, Arruti A, Fernándes-Olmo O (2011) Contribution of point source to trace metal levels in urban areas surrounded by industrial activities in the Cantabria region (Northern Spain). Urban Environ Pollut 4: 76-86.
Srivastava A, Grupta S, Jain VK (2008) Winter-time size distribution and source apportionment of total suspended particulate matter and associated metals in Delhi. Atmos Res 13: 324-330.

Unal YS, Toros H, Deniz A, Incecik S (2011) Influence of meteorological factors and emission source on spatial and temporal variations of $\mathrm{PM}_{10}$ concentrations in Istanbul metropolitan area. Atmos Environ 45: 5504-5513.

US EPA (2000) Meteorological Monitoring Guidance for Regulatory Modelling Applications. EPA-454/R-99-005. February (2000) cit. 18 March 2013, available on: http://nepis.epa gov.

US EPA (1999) Screening level ecological risk Assesment protocol EPA 530-D-99-001-A August (1999).

Viana M, Kuhlbusch T, Querol X, Alastuey A, Harrison RM, Hopke PK, Winiwarter W, Vallius M, Szidat S, Prevot ASH, Hueglin C, Bloemen H, Wahlin P, Vecchi R (2008) Source apportionment of particulate matter in Europe: A review of methods and results. Aerosol Sci 39: 827-849.

Xiao C, Zhang G, Huang D, Ni B, Liu C, Qin Y, Sun H, Wang P, Tian W (2011) Preliminary study on air pollution source identification in Xinzheng, Beijing, using NAA and PIXE. J Radioanal Nucl Ch 291: 95-100.

Zeng F, Shi GL, Li X, Xue Y-H (2010) Application of combined model to study the source apportionment of PM10 in Taiyuan, China. Aerosol Air Qual Res 10: 177-184. 